\title{
On the origin of bistable resistive switching in metal organic charge transfer complex memory cells
}

T. Kever, U. Böttger, C. Schindler, and R. Waser

Citation: Appl. Phys. Lett. 91, 083506 (2007); doi: 10.1063/1.2772191

View online: https://doi.org/10.1063/1.2772191

View Table of Contents: http://aip.scitation.org/toc/apl/91/8

Published by the American Institute of Physics

\section{Articles you may be interested in}

Electrode kinetics of $\mathrm{Cu}-\mathrm{SiO}_{2}$-based resistive switching cells: Overcoming the voltage-time dilemma of electrochemical metallization memories

Applied Physics Letters 94, 072109 (2009); 10.1063/1.3077310

Resistive switching mechanism of $\mathrm{TiO}_{2}$ thin films grown by atomic-layer deposition

Journal of Applied Physics 98, 033715 (2005); 10.1063/1.2001146

Characteristics of different types of filaments in resistive switching memories investigated by complex impedance spectroscopy

Applied Physics Letters 102, 253507 (2013); 10.1063/1.4812811

Reproducible switching effect in thin oxide films for memory applications

Applied Physics Letters 77, 139 (2000); 10.1063/1.126902

Organic electrical bistable devices and rewritable memory cells

Applied Physics Letters 80, 2997 (2002); 10.1063/1.1473234

High switching endurance in $\mathrm{TaO}_{x}$ memristive devices

Applied Physics Letters 97, 232102 (2010); 10.1063/1.3524521

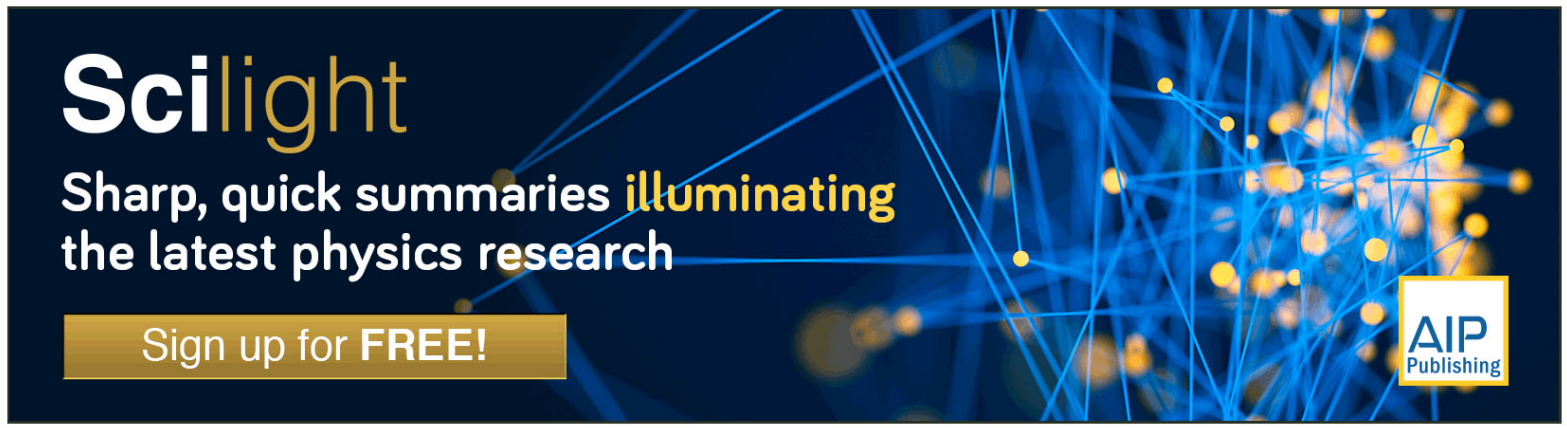




\title{
On the origin of bistable resistive switching in metal organic charge transfer complex memory cells
}

\author{
T. Kever ${ }^{\mathrm{a})}$ and U. Böttger \\ Institut für Werkstoffe der Elektrotechnik, RWTH Aachen, 52074 Aachen, Germany \\ C. Schindler and R. Waser \\ Center of Nanoelectronic Systems for Information Technology (CNI), FZ Jülich, 52425 Jülich, \\ Germany and IFF, FZ Jülich, 52425 Jülich, Germany
}

(Received 5 June 2007; accepted 25 July 2007; published online 22 August 2007)

\begin{abstract}
Electrical characteristics of Cu:tetracyanoquinodimethane (TCNQ) devices with different electrodes were studied. The comparison of impedance spectroscopic measurements on devices with $\mathrm{Al}$ and $\mathrm{Pt}$ top electrodes proved the existence of a high resistive interface layer between Cu:TCNQ and Al. An equivalent circuit was modeled and the resulting values suggest that the interface layer is composed of naturally formed aluminum oxide. Devices with deliberately formed aluminum oxide and without $\mathrm{Cu}$ :TCNQ were fabricated and revealed a similar behavior. The authors propose that the switching effect in $\mathrm{Cu}$ :TCNQ thin film devices is a $\mathrm{Cu}$ ion based electrochemical effect occurring in a thin aluminum oxide layer. ㅇ 2007 American Institute of Physics. [DOI: 10.1063/1.2772191]
\end{abstract}

Resistive switching materials are promising for future high-density nonvolatile memory applications with good downscaling potential. ${ }^{1}$ A lot of different organic material systems have been proposed for use in nonvolatile memories. ${ }^{2}$ Here, we report on the bistable switching phenomena in charge transfer complex thin films consisting of copper as metal donor and tetracyanoquinodimethane (TCNQ) as organic acceptor. Potember et al. first reported electrical field induced resistive switching effects in $\mathrm{Cu}$ :TCNQ thin films sandwiched between copper and aluminum electrodes. ${ }^{3}$

Since then, several groups have observed this switching effect, however, often with different characteristics. Different theories have been proposed while the underlying mechanism is still not clear. Potember et al. postulated that a field induced solid-state reversible phase transition is responsible for this effect. ${ }^{3}$ The low impedance in the on state was attributed to an electrical field induced creation of neutral TCNQ. ${ }^{4} \mathrm{Gu}$ et al. later expanded this theory by using a one dimensional model for overlapping donor and acceptor stacks in the crystalline structure. Heintz et al. showed the existence of two stable structural forms of Cu:TCNQ with distinctive different conductivities. ${ }^{6}$ Some other studies proposed interface effects to be responsible for the resistive switching effect. ${ }^{7,8}$

In the present study, we conduced dedicated control experiments and impedance spectroscopical studies in order to elucidate the role of the TCNQ and the nature of the underlying switching effect. The studied devices were constructed as simple capacitorlike structures. Different bottom electrode materials were deposited on oxidized silicon wafer substrates with thin $\mathrm{NiCr}$ adhesion layers. The Cu:TCNQ thin films were prepared by a physical vapor deposition (PVD) process in a high vacuum chamber. By means of a thermal evaporation technique, $\mathrm{Cu}$ and TCNQ were simultaneously deposited with a ratio of $1: 1$. This PVD method has the advantage that $\mathrm{Cu}$ :TCNQ layers can be deposited on any bottom electrode material. Finally, a shadow mask with circular openings of

\footnotetext{
${ }^{a)}$ Electronic mail: Kever@iwe.rwth-aachen.de
}

$75 \mu \mathrm{m}$ diameter was used to define the top electrode. More details on the deposition process are discussed elsewhere. ${ }^{9}$ Scanning electron microscopy on samples prepared by the simultaneous PVD process displayed dense and uniform $\mathrm{Cu}$ :TCNQ layers. These results were reproducible for the examined film thicknesses $(30-300 \mathrm{~nm})$. Infrared and UVvis spectroscopic measurements were in good agreement to previously published results ${ }^{10}$ and confirmed the formation of a charge transfer complex. X-ray diffraction measurements on all samples revealed an amorphous structure of the $\mathrm{Cu}$ :TCNQ thin films.

All presented electrical measurements were made under ambient conditions until otherwise stated. The currentvoltage $(I-V)$ characteristics were measured with a Keithley 2410 sourcemeter. The impedance spectra in the frequency domain $(100 \mathrm{~Hz}-10 \mathrm{MHz})$ were measured at zero dc bias with a voltage oscillation amplitude of $50 \mathrm{mV}$ using a HP 4194A impedance analyzer.

Samples with identical Cu:TCNQ thin films with a thickness of $200 \mathrm{~nm}$ and varying electrode materials $(\mathrm{Cu}, \mathrm{Al}, \mathrm{Au}$, $\mathrm{Pt}$ ) were electrically characterized. The different devices showed strongly diverse behavior depending on the electrode materials. Memory cells with aluminum top electrodes generally display the lowest conductivity in the pristine and the off state of all tested setups. Resistive switching could be observed in combination with any of the tested bottom electrode materials. Memory cells with a $\mathrm{Cu}$ bottom electrode and an Al top electrode exhibited the most stable and reproducible behavior. This is also by far the most common electrode setup published in literature. A typical $I-V$ curve for such a memory cell is shown in Fig. 1(a). Samples with other bottom electrode materials display qualitatively comparable characteristics. All samples were initially in the high resistive state (HRS) and display a bipolar switching behavior. By application of a more negative voltage than the threshold voltage $\left(V_{\text {th,off-on }}\right)$ to the Al top electrode the memory cell was switched abruptly to the low resistive state (LRS). The memory cell could be switched back by application of a positive voltage greater than $V_{\text {th,off-on. }}$ The ratio HRS/LRS is between 100 and 1000. Both conductance states display a 
(a)

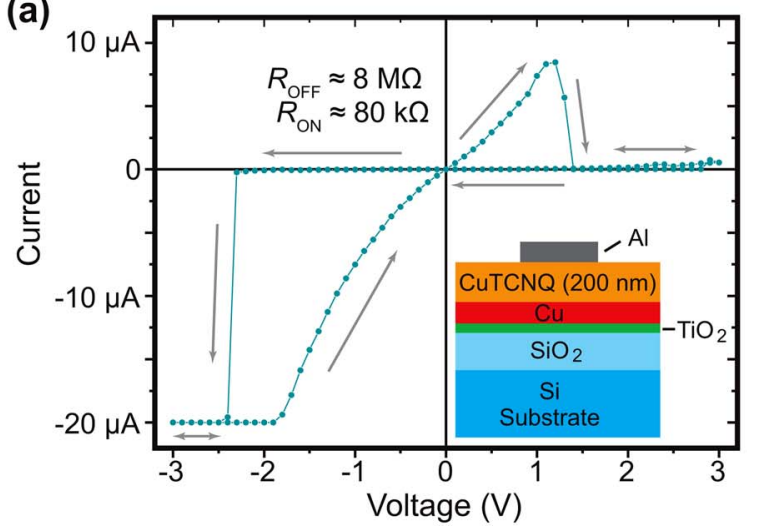

(b)

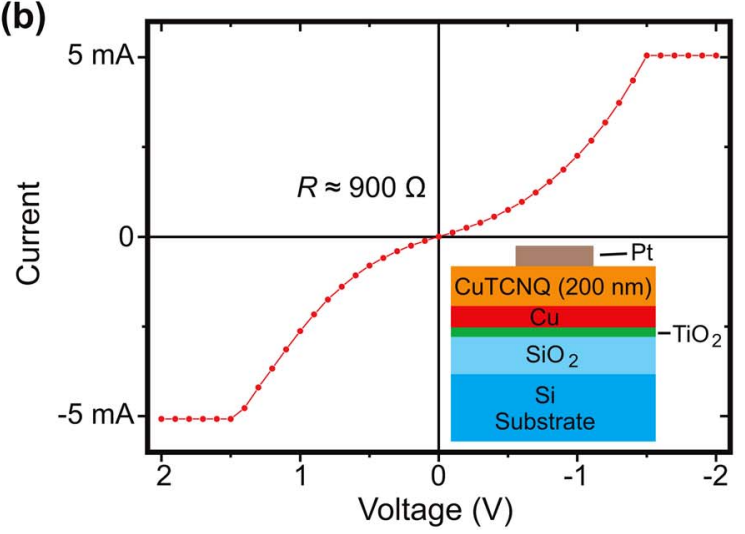

FIG. 1. (Color online) $I-V$ characteristics for different electrode setups. (a) Sample with Cu bottom electrode (BE) and Al top electrode (TE). Current compliance (CC) set to $20 \mu \mathrm{A}$. (b) Sample with $\mathrm{Cu} \mathrm{BE}$ and Pt TE. CC set to $5 \mathrm{~mA}$.

nonlinear current-voltage behavior with an approximately exponential characteristic. Measurements on devices with an inverse setup $(\mathrm{Al} / \mathrm{Cu}$ : TCNQ/Cu) confirmed the polarity dependence (on switching: positive voltage applied to $\mathrm{Cu}$ electrode). Memory cells with noble metal top electrodes generally display completely different characteristics with an order of magnitudes higher conductivity. Samples with Au top electrodes were all in an extreme low resistance state (a few ohms). We attribute this to the migration of Au atoms during the top electrode evaporation process. A typical $I-V$ curve for a sample with $\mathrm{Cu}$ bottom electrode and $\mathrm{Pt}$ top electrode is shown in Fig. 1(b). The conductance is at least 50 times better than the LRS of devices with Al top electrode and hence in better accordance to results published by Melby et al. on bulk Cu:TCNQ. ${ }^{11}$ He observed semiconducting properties with low resistivity values on synthesized Cu:TCNQ bulk crystals. Samples with other bottom electrode materials display comparable characteristics. Temperature-dependent measurements revealed that the conductance behavior is thermally activated. The experiments with different electrode materials indicate that in the examined devices with Al top electrodes the resistance is dominated by the interface to the top electrode.

In order to further examine the interface properties, impedance spectra of the test structures were recorded on devices with top electrode areas of $0.018 \mathrm{~mm}^{2}$. The thin film impedance $\left(Z_{\mathrm{TF}}\right)$ of samples shown in the inset of Fig. 1(b) can be described by a simple equivalent circuit consisting of

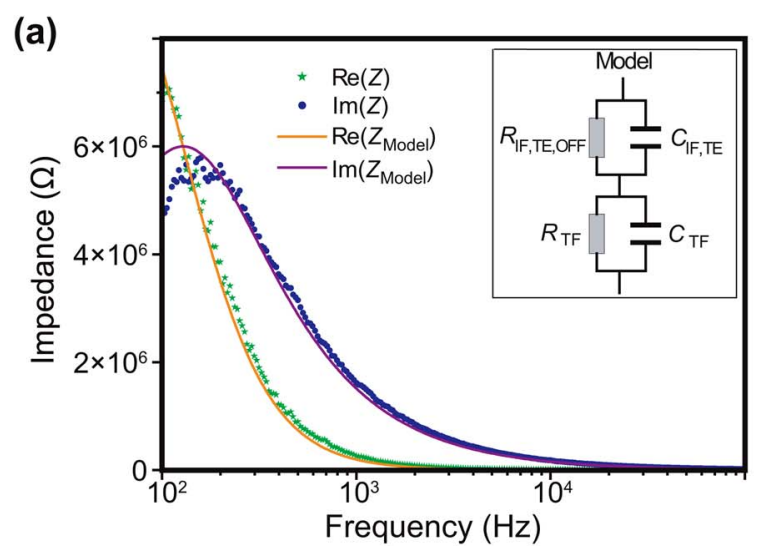

a parallel connection of a capacitance $\left(C_{\mathrm{TF}}\right)$ and a resistance $\left(R_{\mathrm{TF}}\right)$,

$$
Z_{\mathrm{TF}}=\frac{R_{\mathrm{TF}}}{1+\omega^{2} R_{\mathrm{TF}}^{2} C_{\mathrm{TF}}^{2}}-j \frac{\omega R_{\mathrm{TF}}^{2} C_{\mathrm{TF}}}{1+\omega^{2} R_{\mathrm{TF}}^{2} C_{\mathrm{TF}}^{2}} .
$$

With the assumption of a simple parallel plate capacitor the measurements result in a dielectric constant of $\epsilon_{r}=1.26$. The resistivity calculates to $\rho \approx 20 \Omega \mathrm{m}$ with linear assumption. Measurements on identical samples with the only difference being the top electrode material, $\mathrm{Al}$ instead of $\mathrm{Pt}$, displayed distinctive different results. The frequency dependence of the real and imaginary part of the impedance is shown in Fig. 2 for the HRS (a) and LRS (b). For this kind of memory cell, we extend the simple model used in Eq. (1) by a second $R C$ element in series with the first one, as shown in the inset of Fig. 2. One such element represents the conducting, homogeneous bulk with the interface to the $\mathrm{Cu}$ bottom electrode. In a first approach, we can set the values of this element to the results of the $\mathrm{Cu} / 200 \mathrm{~nm} \mathrm{Cu}$ :TCNQ/Pt memory cells $\left(R_{\mathrm{TF}}=1000 \Omega, C_{\mathrm{TF}}=2 \times 10^{-12} \mathrm{~F}\right)$. The second element represents the interface to the $\mathrm{Al}$ top electrode $\left(R_{\mathrm{IF}, \mathrm{TE}}, C_{\mathrm{IF}, \mathrm{TE}}\right)$. For this model, the real and imaginary parts of the impedance can be calculated to

$$
\operatorname{Re}\left\{Z_{\text {model }}\right\}=\frac{R_{\mathrm{TF}}}{1+\omega^{2} R_{\mathrm{TF}}^{2} C_{\mathrm{TF}}^{2}}+\frac{R_{\mathrm{IF}, \mathrm{TE}}}{1+\omega^{2} R_{\mathrm{IF}, \mathrm{TE}}^{2} C_{\mathrm{IF}, \mathrm{TE}}^{2}},
$$

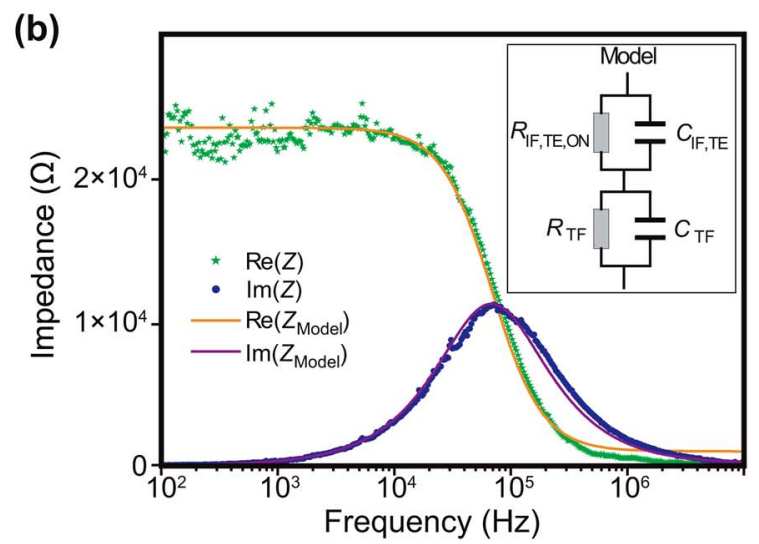

FIG. 2. (Color online) Frequency dependence of the real and imaginary parts of the impedance of a sample with $\mathrm{Cu} \mathrm{BE}$, a $200 \mathrm{~nm} \mathrm{Cu}$ :TCNQ layer, and Al TE. (a) Memory cell in HRS. (b) Memory cell in LRS. 


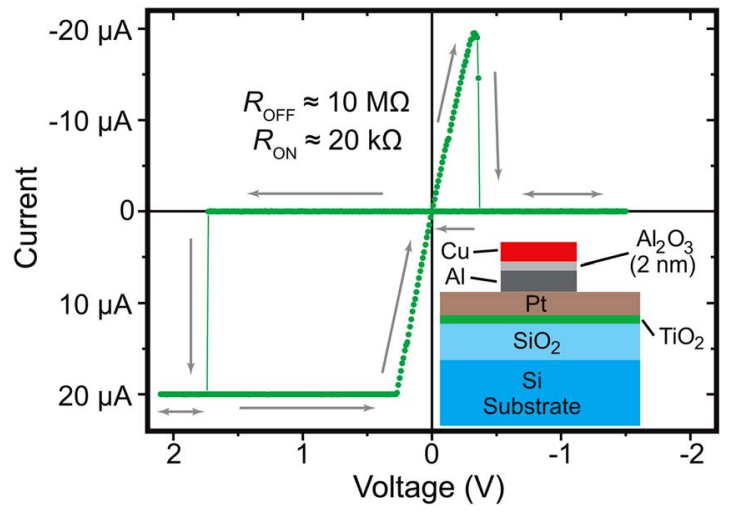

FIG. 3. (Color online) $I-V$ characteristic for a sample with $\mathrm{Al} \mathrm{BE}$, a $2 \mathrm{~nm}$ thin $\mathrm{Al}_{2} \mathrm{O}_{3}$ instead of $200 \mathrm{~nm} \mathrm{Cu}: \mathrm{TCNQ}$, and a Cu TE. CC set to $20 \mu \mathrm{A}$.

$$
\operatorname{Im}\left\{Z_{\text {model }}\right\}=\frac{\omega R_{\mathrm{TF}}^{2} C_{\mathrm{TF}}}{1+\omega^{2} R_{\mathrm{TF}}^{2} C_{\mathrm{TF}}^{2}}+\frac{\omega R_{\mathrm{IF}, \mathrm{TE}}^{2} C_{\mathrm{IF}, \mathrm{TE}}}{1+\omega^{2} R_{\mathrm{IF}, \mathrm{TE}}^{2} C_{\mathrm{IF}, \mathrm{TE}}^{2}} .
$$

The fitted curves for both the real and imaginary parts of the impedance are shown in Fig. 2 for HRS (a) and LRS (b). The fitting results in $R_{\mathrm{IF}, \mathrm{TE}, \text { off }}=1.2 \times 10^{7} \Omega$ for HRS and $R_{\mathrm{IF}, \mathrm{TE}, \mathrm{on}}=22.5 \mathrm{k} \Omega$ for LRS. The value of the capacitance is constant in both states $\left(C_{\mathrm{IF}, \mathrm{TE}}=1.04 \times 10^{-10} \mathrm{~F}\right)$. Calculated with the assumption of a parallel plate capacitor model, this results in a quotient of $\epsilon_{r, \mathrm{IF}, \mathrm{TE}} / d_{\mathrm{IF}, \mathrm{TE}}=0.52 \mathrm{~nm}^{-1}$ for the unknown thickness and dielectric constant of the interface. The result calculates to an interface layer of a few nanometer thickness and a dielectric constant between 1.5 and 3. These values match to an interface layer of naturally oxidized aluminum between $\mathrm{Cu}$ :TCNQ and the aluminum top electrode. This $\mathrm{Al}$ oxide film may be formed by oxygen adsorbed and entrapped by the $\mathrm{Cu}$ :TCNQ layer and the ex situ deposition of the $\mathrm{Al}$, which is the typical process of the $\mathrm{Cu}$ :TCNQ cells reported in the literature. These results are in good accordance to previously published results on resistive switching in rose bengal molecular devices. ${ }^{12}$ The switching in these devices is attributed to the formation of a thin aluminum oxide layer between the top electrode and molecular layer. Cölle et al. proposed a similar mechanism for spin-coated polymeric films. ${ }^{13}$

To verify our assumption, we fabricated in situ samples without $\mathrm{Cu}$ :TCNQ with only a thin $(\approx 2 \mathrm{~nm})$ aluminum oxide film between the electrodes. The aluminum bottom electrode was sputtered through a shadow mask on top of a continuous Pt layer. The surface of the aluminum was then controlled oxidized by UV treatment in oxygen atmosphere (50 mbars). Finally the $\mathrm{Cu}$ top electrodes were sputtered. The device setup is shown in the inset of Fig. 3. The current voltage characteristic (Fig. 3) is remarkably similar to the $\mathrm{Cu}$ :TCNQ devices [Fig. 1(a)]. Endurance measurements displayed a better switching stability for devices with Cu:TCNQ ( $\geqslant 1000$ cycles) and a better yield than for samples with only a thin aluminum oxide layer
( $\leqslant 50$ cycles). It is important to note that the on switching occurs for a negative voltage polarity applied to the $\mathrm{Al}$ electrode in all cases. This is well known for resistively switching electrochemical metallization cells and reflects the drift of $\mathrm{Cu}$ ions through the amorphous aluminum oxide layer, the cathodic reduction, and growth of $\mathrm{Cu}$ filaments toward the anode. ${ }^{14-17}$ First results of further control experiments with an aqueous solution of $\mathrm{CuSO}_{4}$ top electrode suggest that aluminum oxide represents the electrolyte which mediates a $\mathrm{Cu}$ ion based electrochemical switching.

In conclusion, we confirmed earlier reports ${ }^{7,8,13}$ about the decisive role of a thin interfacial aluminum oxide layer at the $\mathrm{Al}$ electrode by these experiments. We supplement this theory by additional experiments which indicate that the switching effect in $\mathrm{Cu}$ :TCNQ thin film devices could be a $\mathrm{Cu}$ ion based electrochemical effect, i.e., the devices could be described as electrochemical metallization cells, where the aluminum oxide represents the electrolyte. The Cu:TCNQ layer appears to be a suitable spacer, which possibly stabilizes the reversible switching by acting as a $\mathrm{Cu}$ ion buffer. However, the TCNQ does not appear to be essential for the switching process.

The authors thank Robert Müller (IMEC) for fruitful discussions. This research was performed within the framework of the EMMA project of the European Commission (FP6033751).

${ }^{1} \mathrm{R}$. Waser, Nanoelectronics and Information Technology (Wiley-VCH, Weinheim, 2003), p. 532.

${ }^{2}$ J. C. Scott and L. D. Bozano, Adv. Mater. (Weinheim, Ger.) 19, 1452 (2007).

${ }^{3}$ R. S. Potember, T. O. Poehler, and D. O. Cowan, Appl. Phys. Lett. 34, 405 (1979)

${ }^{4}$ W. M. Risen, C. H. Tzinis, and E. I. Kamitsos, Solid State Commun. 42, 561 (1982)

${ }^{5}$ Z. Gu, H. Wu, Y. Wie, and J. Liu, J. Phys. Chem. 97, 2543 (1993).

${ }^{6}$ R. A. Heintz, H. Zhao, X. Ouyang, G. Grandinetti, J. Cowen, and K. R. Dunbar, Inorg. Chem. 38, 144 (1999).

${ }^{7}$ T. Oyamada, H. Tanaka, K. Matsushige, H. Sasabe, and C. Adachi, Appl. Phys. Lett. 83, 1252 (2003).

${ }^{8}$ J. J. Hoagland, X. D. Wang, and K. W. Hipps, Chem. Mater. 5, 54 (1993).

${ }^{9}$ T. Kever, C. Nauenheim, U. Böttger, and R. Waser, Thin Solid Films 515, 1893 (2006).

${ }^{10}$ S. Sun, P. Wu, and D. Zhu, Thin Solid Films 301, 192 (1997).

${ }^{11}$ L. R. Melby, R. J. Harder, W. R. Hertler, W. Mahler, R. E. Benson, and W. E. Mochel, J. Am. Chem. Soc. 84, 3374 (1962).

${ }^{12}$ S. Karthäuser, B. Lüssem, M. Weides, M. Alba, A. Besmehn, and R. Oligschlaeger, and R. Waser, J. Appl. Phys. 100, 094504 (2006).

${ }^{13}$ M. Cölle, M. Büchel, and D. M. de-Leeuw, Org. Electron. 7, 305 (2006).

${ }^{14}$ S. Kaeriyama, T. Sakamoto, H. Sunamura, M. Mizuno, H. Kawaura, T. Hasegawa, K. Terabe, T. Nakayama, and M. Aono, IEEE J. Solid-State Circuits 1, 168 (2005).

${ }^{15}$ M. N. Kozicki, C. Gopalan, M. Balakrishnan, and M. Mitkova, IEEE Trans. Nanotechnol. 5, 535 (2006).

${ }^{16}$ S. Dietrich, M. Angerbauer, M. Ivanov, D. Gogl, H. Hoenigschmid, M. Kund, C. Liaw, M. Markert, R. Symanczyk, L. Altimime, S. Bournat, and G. Mueller, IEEE J. Solid-State Circuits 42, 839 (2007).

${ }^{17}$ C. Schindler, S. C. Puthen Thermadam, Rainer Waser, and Michael N. Kozicki, IEEE Trans. Electron Devices (to be published). 